\title{
Becoming (Hetero) Sexual? The Hetero-Spectacle of Idollators and their Real Dolls
}

\author{
Allison Burr-Miller • Eric Aoki
}

Published online: 18 May 2013

(C) The Author(s) 2013. This article is published with open access at Springerlink.com

\begin{abstract}
Guys and Dolls, a BBC documentary premiering in 2007 sketches out the lives of four men in relationships with silicone-fleshed, anatomically correct Real Dolls (RDs). The men in the documentary treat their RDs as if they are alivethey dress their dolls, rub their feet, and discuss what sex and the relationship with their dolls is like. In relating with their RDs, the men respond to concerns of having "no female company" at all. In this essay, combining Stein's (Sexualities and society: a reader, Polity Press, Oxford, pp 132-142, 2003) notion of "be-coming out," with Deleuze and Guattari's (A thousand plateaus: capitalism and schizophrenia, University of Minnesota Press, Minneapolis, 1987) theory of becoming, we contend that the documentary actively represents the men's pasts in order to make sense of, justify, and construct the dynamics of their current sexual selves. Because the idollator's be-coming narratives illuminate their heteronormative shortcomings, these sexual origin stories take a confessional tone. Although confessions regarding
\end{abstract}

An early iteration of this essay was first presented at the 2008 meeting of the National Communication Association in San Diego, California.

Allison Burr-Miller and Eric Aoki have contributed distinctly and equally to the progression and development of this essay.

\footnotetext{
A. Burr-Miller $(\bowtie)$

Department of Communication, University of Massachusetts Amherst, 240 Hicks Way, Amherst, MA 01003-9278, USA

e-mail: allison.burrmiller.04@cnu.edu; aburrmil@comm.umass.edu

E. Aoki

Department of Communication Studies, Colorado State University, 218 Willard Eddy Hall, Fort Collins, CO 80523-1783, USA

e-mail: Eric.Aoki@colostate.edu
} 
sexuality are not soul cleansing acts but are approval seeking performances that reify normative social boundaries, we argue for a queer reading of the Guys and Dolls text which subverts the dominant logic of heteronormativity.

Keywords Heteronormativity - Gender performativity - Sexuality · Idollators · Guys and Dolls

\section{Introduction}

Guys and Dolls, ${ }^{1}$ a documentary premiering in 2007 sketches out the lives of four men in relationships with silicone-fleshed, anatomically correct Real Dolls (RDs) Abele and Holt (2007). The men name their dolls and treat them as if they are alive. Guys and Dolls' coverage of the idollator co-culture displays men dressing their dolls, rubbing their feet, replacing their tongues, and discussing what sex and the unidirectional, constructed relationship with their dolls is like. As noted in the documentary, every year a small California-based company manufactures and sells 400 life-sized sex dolls to customers world-wide. Creator of these Real Dolls (RDs), Matt, states, "Most people that say that they wouldn't ever have sex with a doll, absolutely would." Noting that some guys cannot talk to a "girl," Matt contends having sex with "a piece of rubber that's exactly shaped like and feels like a woman" is better than never having sex. In Matt's words, for them, "it's enough."

In this essay we argue that the discursive style employed by the men in the documentary to narrate the details of their relationships with RDs is a productive part of idollator sexuality in Guys and Dolls. ${ }^{2}$ Adopting Deleuze and Guattari's (1987) theory of becoming along with Stein's (2003) notion of "be-coming out" as a "practical creation of self ... [in which] individuals reflexively effect change in the meanings of particular identities" (p. 132), we contend that the men in Guys and Dolls actively re-present their past in order to make sense of, justify, and construct the dynamics of their current sexual and relational selves. In so doing, the men offer confessions of their sexuality while performing a mode of becoming heterosexual within the documentary. More than unveiling hidden desire, the men's narratives are constitutive of their sexual subjectivity rather than a consequence of it. $^{3}$

The idollators' RD narratives are constantly naturalizing and reifying the twosexed system upon which heterosexuality relies. Entering the contained environment of their homes the documentary depicts how the idollators use the dolls as technologies to become heterosexual. Central to the process of the men of Guys and

\footnotetext{
1 We use the title "Guys and Dolls" as it originally aired in Britain on Channel 5. "Love Me, Love My Doll" is the title associated with the British Broadcasting Corporation (BBC) America documentary of the same text and topic. The latter title is important to attend to, however, because as we will illuminate in this essay, embedded in the discourses of the four men highlighted in the documentary is a declaration of the ideologically-driven need and challenge of being accepted by the opposite sex and society more generally.

${ }^{2}$ Meyer (2007) argues that identity can be understood as processional-as a constant process of disclosure and reflexivity.

3 In this essay we use Rubin's (1984) charmed circle as a model of heteronormativity.
} 
Dolls becoming heterosexual is the production of a sexual Other. While Dunne (2003) argues that all heterosexuality is an illusion upheld by the production of two sexes through the culturally learned "suppression of similarities between them" (p. 60), in the absence of real women the idollators must discursively construct their dolls into women as a way of making themselves into men. The sexual difference through which the idollators are constructed is grounded in "a necessary female absence" (Halperin 1990, p. 149); in an interesting paradox to heterosexual logic, Halperin (1990) contends that the reproduction of masculine hegemony has long relied on this absence. Halperin demonstrates this point in his reading of the character Diotima in Plato's Symposium. Puzzled by Plato's decision to make Diotima (who is an expert on male paederasty) a female character, Halperin argues that she is a "cooptation of 'the feminine'... to license male speech" (1990, p. 145). Instead of bringing in an actual female voice Plato's Symposium controls the scope of feminine becoming by impersonating "woman" in order to "represent [her] in a form that is recognizable to men" (Halperin 1990, p. 146). For Halperin, men's attempts to reproduce or "retain their identity as men," then, is dependent not on the presence of a sexual Other but on control over the symbolic economy through which they "explain themselves and their desires to one another" (1990, pp. 146-147). As we will illuminate in our analysis of the discourses of the four men, the narratives the idollators construct about their RDs is precisely this attempt to fabricate a feminine vessel in the service of a legitimately masculine and heterosexual identity formation.

Because the idollators' becoming narratives foreground their heteronormative shortcomings, these sexual origin stories have a confessional tone as the men are entering a vulnerable situation by disclosing significant information about who they really are to a potentially disapproving audience (Battles and Hilton-Morrow 2002; Dow 2001; Carrion and Lock 1997; Jolly 2001; Patton 1993; Sedgwick 1990). Rather than soul cleansing acts, confessions regarding sexuality are approval seeking performances that often reify normative social boundaries by contributing to regulatory discourses which constrain how queer identities can be enacted and known (Dow 2001; Foucault 1978). Although the men of Guys and Dolls attempt to justify their decisions to potential viewers, and even acknowledge that it is easy for others to perceive them as strange, the power of regulatory discourses seems to highlight the oddity of even the most reflexive of the idollators. As such, we assert that media are also a means by which sexual co-cultures become objects of voyeurism. In concluding the essay, we employ the term hetero-spectacle to refer to this voyeuristic consumption of confessional coming out narratives. Because confessions reproduce the status quo through the revealing and categorizing of deviant practices, the idollators' performance of becoming serves as an anchor and cue for the heteronormative gaze. But while removing these men from the highly contained conditions of their homes exposes them to the scornful stare of the heterospectacle, the documentary's representation of the idollators equally functions to destabilize the myth of a natural, monolithic heterosexuality. That is, in showing the idollators going to such lengths to reproduce heterosexual order the documentary exposes the capriciousness of its logic. 


\section{Narrativizing Bodies: Becoming Sexual Subjects}

We assess the ways the men in Guys and Dolls narrativize their bodies by combining the previously discussed theory of "be-coming out" (Stein 2003) with the notion of becoming as developed by Deleuze and Guattari (1987). Doing so allows us to demonstrate how models of identity-including, in this case, highlighting sexual and gender identity - cannot be explained by theories of origin and binary logic but through a process of connection, disconnection, partial connection, and reconnection. Becoming, then, is a process of varying connective forms in which the contours, logics, and means by which connections are forged are a constitutive part of any stoppage in meaning, any moment of perceived coherence. As opposed to assuming that things in the world have stable meaning and form in and of themselves prior to encountering difference, Deleuze and Guattari argue that difference is the motivating force behind the trajectory of becoming. The perception of difference inspires the formation of pathways that accentuate, subvert, rework, and make anew the directions and intersections where difference comes to mean and matter, though difference is not fixed or eternal.

Scholars have previously noted that popular beliefs about sexuality perceive it as a natural, even sacred, expression of attraction and desire (Foucault 1978; Jackson 2003; Simon 2003; Weeks 1986). As we witness with the men in Guys and Dolls, this thinking is due, in large part, to the evidence that bodily difference provides in support of the existence of men and women and thus the irrefutable naturalness of heterosexuality. For us, then, observing the ways that these assumed natural desires are put into discourse provides an opportunity to understand how the idollators be-come sexual subjects through the narrativizing of their bodies, desires, and reflections. It seems as though examining such narratives not only provides credence to McLean's (2007) assertion that the material reality of individual sexual identity and desire are rarely as clear cut or fixed as the labels heterosexual, homosexual, and bisexual suggest but equally that these labels provide order (or blinders) to ways individuals can imagine their gendered and sexual selves. As we will see with the men in Guys and Dolls their discourse is recognizably queer (that is, it is located "betwixt and between" (Turner 1974) the normabiding content of human sexuality) but far from exhausts the ways individuals can narrativize themselves and be-come sexual subjects (Stein 2003).

According to Gross (2005), scholars of communication during the 1970s and 1980s not only argued to de-pathologize alternative sexualities but contended that sexuality, in general, is a culturally contingent phenomenon whose parameters of existence and meaning are entirely context dependent. Similarly, queer theorists work to recognize and make productive the lives of "anyone who did not fit into society's confining sexual roles or play by society's restrictive sexual rules" rather than to fix their bodies to conform to an idealized cultural standard (Gross 2005, p. 515). For instance Sloop (2004) notes in his examination of the infamous John/ Joan case that bodies are guided (sometimes surgically) from birth to fit the script of heteronormativity. ${ }^{4}$ Naturalizing the seemingly ordinary progression of a

\footnotetext{
${ }^{4}$ Sloop (2004) explores the 1969 John/Joan case in his book Disciplining Gender. Sloop summarizes that a child born a boy had a portion of his penis accidentally cut off by a doctor. The parents, at the advice of doctors who thought it would be easier to construct female genitals than reconstruct male genitals, decided to reassign the sex of their son. Early popular and medical journals (including the often debated
} 
heteronormative lifestyle, however, fails to recognize the temporalities and spatialities that characterize the practices of many queer bodies that are "unscripted by the conventions of family, inheritance, and child rearing" (Halberstam 2005, p. 2). As such, lifestyles that do not fit the norm because they are queer- "non normative behaviors" including but not necessarily or limited to those performed by sexual minorities - are often read as dangerous and immature (Halberstam 2005, pp. $5-6) .^{5}$

One of the most foundational concepts in queer theory's quest to destabilize heteronormativity is Rubin's (1984) charmed circle. For Rubin, the charmed circle is a metaphor for the romantic and sexual practices accepted within a given culture and throughout history humans have created, and continue to create, a "sexual value system" (1984, p. 280). Contemporary Western renderings of this value system place heterosexual, married, monogamous, consensual, procreative, and private sexual intercourse at the center of the charmed circle (Rubin 1984). Meanwhile, Rubin's charmed circle suggests that other forms of sexual behavior such as oral sex, homosexual sex, or sex that involves toys are considered abnormal, unnatural, and immoral.

Like most theories, Rubin (1984) concedes that the charmed circle outlines a set of generally accepted perceptions about sexual behavior rather than serving as a steadfast set of guidelines that describes the sex lives of most people. In fact, notes Rubin, the breadth of sexual variation is elided under a singular monolithic conception of heterosexuality thus allowing for the boundaries of what constitutes normative sex to be simultaneously expanded and stringently policed. One need not dig deep to uncover the Foucauldian logic of Rubin's charmed circle. The charmed sexual practices support the reproduction of current economic, familial, and social systems and thus act as the behaviors through which "truth and sex are joined" (Foucault 1978, p. 61). Meanwhile, through the production of certain sexual practices as deviant and outlier the logic of heterosexuality as natural is upheld.

Butler's (1990) theory of gender performativity sheds further light on the discursive managing of bodies in ways that maintain the heteronormativity of culture. Conceptualizing gender as a performed iteration which conforms to particular recognizable standards of how we should look, think, and act, performativity draws attention to the gender governing function of the terms that seemingly make plain the form of a subject's genitalia-male/female, man/woman. Butler demonstrates that gender does not follow from a subject's innately coherent existence as a man or a woman. Rather coherence as a male or a female is a

\footnotetext{
Footnote 4 continued

research by Money (1975)) read the child's gender performance through a constructivist paradigm, as feminine. However, in 1997, when David Reimer (John/Joan) found out that he was born male, he had a second reassignment surgery, allegedly correcting his sex. Still relying on behaviors marked by society as expressive of gender (hair, clothing style, physical activities), Diamond and Sigmundson (1997) refuted Money's initial findings and argued that this case was evidence that gender is biologically determined.

5 Consistent with Foucault's (1978) rendering of “normalizing discourses," Halberstam's (2005) understanding of queer includes "nonnoramtive behaviors" performed by any subject (p. 6). For instance, an unemployed or homeless person could be queer under Halberstam's definition because their life script does not (in that moment) fit that of a heteronormative subject's.
} 
retroactive illusion that follows from an individual's ability "to conform to the gendered norms of cultural intelligibility by which persons are defined" (Butler 1990, p. 17). As individuals performatively cite the respective cultural expectations and idealizations for their sex, they fuel the illusion that the gendered subject exists prior to the translation of "actions, gestures, and speech" as expressive of gender (Butler 1995, p. 31). Crucially then, this reiteration of sexual difference through the performance of gender norms needs to be understood as a regulatory practice that naturalizes bodies as fixed in their sexed contours. Far from experiencing a recognizable split between our gendered selves and our sexed bodies, the two are an indistinguishable product of a constant normalized doing and becoming in which the body itself cannot be "thinkable apart from the materialization of that regulatory norm... which qualifies a body for life within the domain of cultural intelligibility" (Butler 1993, pp. 1-2).

Despite Butler's (1993) enormously influential claims that gender can be a "critical resource" in the destabilization of heterosexuality and the struggle to rearticulate "what counts as a valued and valuable body in the world" (pp. 3 and 22), Halberstam (1998) argues that there still seems to be difficulty with conceptualizing masculinities when they are not associated with male bodies. For instance, Connell (2003), who is credited with recognizing masculinity and femininity as multiple and multifaceted rather than singular and monolithic, defines masculinities' object of knowledge as “men's places and practices in gender relations" [emphasis original] (p. 47). In a significant shift away from "this collective failure to imagine" masculinity outside of the confines of male bodies Halberstam contends that masculinity "becomes legible as masculinity where and when it leaves the white males middle-class body" (1998, pp. 2 and 15). When masculinity is conceived of as the product of male bodies, the masculinities performed by women are invalidated as gender deviance and simulations of maleness rather than something "produced by, for, and within women" (Halberstam 1998 , p. 15). Additionally, scholarship on the fluctuation of gender and sexual norms depending on historical context and (co-)cultural codes describes practices that address Butler (1993) and Halberstam's concerns regarding gender's indispensable role in destabilizing the naturalized link between genitalia, bodily performance, and sexuality (Hale 2003; Halperin 1990).

In the following analysis of BBC's Guys and Dolls, we employ the logic of becoming to examine the narrative construction of the idollators as (hetero)sexual subjects. Similar to Hale's (2003) assertions regarding leatherdyke participants, idollator gender and sexual identity are also dependent on the containment of bodies within a particularized context. Within the highly constrained situations of the bedroom and home, idollator and RD bodies become operative in ways they likely could not within dominant society. Relying on bodily difference and discursive patterns of heteronormative desire, the idollators become heterosexual. However, overcoming the absence of a literal woman requires the idollators to project femininity onto an anatomically correct plastic vessel. Such an overt example of Barthes' woman as "metaphor without breaks" destabilizes the pre-discursive truth of the two-sexed system as the idollators' construction of gender onto a simulated woman foregrounds the arbitrary relationship between the body and the gendered 
subject (Jardine 1985). ${ }^{6}$ This being the case, the idollators' production of the sexual Other in their becoming heterosexual at once obeys and disrupts the heterosexual matrix. Once taken out of their sterile environment and infused with the judgment of Rubin's (1984) charmed circle, the idollator/RD relationship violates many of the guidelines that grant access to the landscape of heteronormativity. As depicted in the documentary, the presence of toys, lack of human connection, and gender performativity necessary for the idollators to simulate heterosexuality are equally contributing factors that debunk the legitimacy of their relationships.

\section{Methodological Anchors: Ways of Looking and Reading}

Ott and Aoki (2004) anchor our method and procedure for looking and reading by offering the critical question: "what is a film doing and how?" (p. 151). Additionally, Benson and Anderson (1989) motivate our assessment of the film's "constructed invitation" (p. 3). Ott and Aoki assert that media critics work to "reasonably provide an account of the shared experience a film fosters" by unpacking "subject positions with which viewers are solicited to identify" (2004, p. 151).

With regard to our practice here, there are three methodological procedures that organized our way of looking and reading the text: first, both authors viewed the text two or more times on our own while taking notes on the character discourses and filmic structures made within the documentary; second, a written transcript of key discourses and frames within the documentary was produced for each other's use in their assessment of emergent themes and preferred readings; third, both of us viewed the text in each other's presence to begin the conversation of what discourse and filmic points in the documentary become emphasized, repeated, differentiated, and distinct as units in the narratives of the men's discourse and the film's production; and, finally, we wrote up discourse and character profiles for each man and the overall documentary architecture using consistent interpenetration of analysis and interpretation (Lofland et al. 2006) to move toward our argument of the substantiated preferred reading of the documentary (Ott and Aoki 2004). What follows, then, is our critical reading of both the filmic structure and character narratives of the documentary.

\section{Becoming Heterosexual: Four Men and Many Dolls}

In the opening fifty-seconds of the BBC documentary, Guys and Dolls, the narrator sets the scene for the four men and their stories of life with their Real Dolls:

For some people, finding a partner in life can be difficult. For others, it's almost impossible. Ten years ago, a small factory in California began making an alternative

\footnotetext{
${ }^{6}$ Jardine (1985) uses this phrase originated by Barthes to argue that the category 'woman' has "infinitely expanded" through the rampant application of the concept "feminine" to everything new and unknown (pp. 35-36).
} 
partner; each is tailor-made to suit every taste...There are now three thousand Real Dolls across the world, providing some owners with the love and companionship that real women cannot.

The first RD owner, Davecat, is introduced within a shot of a classic, two-story home in "Michigan, USA" (a shot complete with the sounds of birds chirping, a blue sky, trees, and a highly manicured lawn). Following this opening image, the viewer is allowed more closely into the lives of the four men-Davecat, Everard, Gordon, and Mike.

In the section that follows we first examine the sexual origin stories told by each of the four men and the ways that those narratives reproduce the naturalized status of heterosexuality. Ultimately, however, their heteronormative shortcomings indicated in the explanation of their RDs invites a heterosexist gaze that at once reinforces and destabilizes the logic of a natural, monolithic (hetero) sexuality.

\section{Davecat}

Davecat's RD narrative begins as soon as he is introduced to the documentary's audience. Slight, alternative-looking, and feminine in his performance of masculinity, Davecat indicates that he has had to learn to adjust to his (un)conventional relationship with his RD, Chichan, while living in his parents' home. Although he never seems to question his status as a heterosexual man, Davecat assesses his current day life, and we are given a clear sense that he is dealing with the parental disapproval that accompanies many queer relationships. He summarizes,

The thing my father finds really difficult, about my relationship with [Chichan] is the fact that she's not alive...she's not a human being. He sees it as unnatural and strange, and, uh, he's the sort of person to whom strange is something to be avoided.

As a result of parental clashes, Davecat tells the camera that Chichan spends "99.9\% of her time in my room." 7 Notably, Davecat reads his parents as disapproving of Chichan rather than of him. He interprets his parents discourse through the heterosexual narrative of disapproval in which Chichan is not "the one" for their son rather than through a narrative that constructs Davecat as sexually deviant.

Once Davecat has explained his current relationship with Chichan, he discloses the origin of his attraction to the RD. Davecat suggests he has always had an "innate interest in synthetic humans even back at an early age." Davecat recounts a particular moment from his childhood when he went to a department store with his mother and was "found talking to a mannequin lass in a tennis skirt." Flipping through photos of synthetic women as he tells this narrative, Davecat proposes that what he finds erotic about mannequins is their incorruptible beauty and stoicism, qualities that have led his attempts to date real women to be "half-hearted."

\footnotetext{
7 Davecat's parents' insistence that he keep Chichan out of sight speaks to the weight of heteronormativity as discussed in Berlant and Warner's (1998) "Public Sex."
} 
These accounts threaded together by Davecat serve as origin moments that justify and provide continuity for his current sexual subjectivity. Davecat's origin story operates to reveal that his attraction to his RD differs from the norm but is true to who he is. Interestingly, despite his lack of interest in real women, Davecat's discursive production of Chichan reproduces heterosexuality's two-sexed system. As a result, his discourse at once highlights and masks his heteronormative shortcomings.

Davecat's discussion of Chichan is the most heteronormative of the four idollators represented in BBC's documentary. He continually draws from discourses of fidelity associated with idealized Hollywood versions of monogamous heterosexual love; his is the story of fairytale love. We see Davecat kissing Chichan, rubbing her feet, and speaking of lying in bed "appreciating" her. Rather than highlighting the RD's sexual function, Davecat foregrounds the relational aspect of the dolls as the reason idollators have their RDs while also calling for others to understand:

It's (owning a RD) the difference between being alone and lonely; being alone is one thing, I don't mind being alone at all, however, I cannot stand being lonely...that's something that more people, I would hope would understand, that that's why idollators have their dolls.

Later in the documentary, Davecat makes the difficult decision to send Chichan away for repair. In addition to the clichéd relationship format, the exoticness of Chichan's name, her long, straight hair, her small stature, and her ability to "regard" Davecat all follow standard discourses of the feminine role in a heterosexual relationship. Davecat's use of the endearing term "sweetie" to refer to Chichan and his description of being reunited with her as their "second honeymoon" add to the accumulation of signs around Chichan that emphasize her femininity, his attraction to her, and the romantic notions of fidelity and loyalty.

The documentary's dramatic representation of Chichan's departure and reunion with Davecat highlight Davecat's glaring violation of the charmed circle. Davecat constructs a heterosexual world for himself in spite of the charmed circle's rules regarding toys, consent, and male/female pairings. Paradoxically, Davecat's narrative production of difference between real women and RDs is the driving force behind his attempts at becoming heterosexual. While he accepts heterosexuality's production of women as a singular group (opposite of men), he rejects human women as requisite for heterosexual love. With no one to play along to confirm his reality, Davecat's recitation of heteronormative coded discourses and acts can motivate his becoming heterosexual only within the privacy of his room.

\section{Everard}

Leaving Davecat happily ever after with Chichan, the documentary shifts to fiftyyear old Everard. With the introduction of Everard, the documentary reveals a modern, two-story home in Dorset, England. The narrator informs us that Everard's mother, Katheline was the last person with whom Everard lived and is an essential character in his RD narrative as it is clear his need to please her continues to 
influence his life. Everard discusses how he keeps her room like it was at the time of her passing; he notes, it "helps me, ah, remember, ah, I suppose, remember it as, when she was alive." We learn that Everard attributes his current way of life to not learning to "cope" when someone we love dies. As he reflects on his life with a RD and on his mother's imagined approval, Everard asserts, "she'd probably prefer it if I had a real woman, but ah, I think she'd rather I had Real Dolls than just remain completely without any female company at all."

Like Davecat, Everard's sexual origin story is motivated by a fear of loneliness. But whereas the viewer learns of Davecat's preference for RDs over real women, Everard tells a story of his past that represents women as unattainable; he states, "When I'm in a place where there's some attractive looking women around they're all unattainable as far as I can tell. Having my Real Dolls at home makes it not so bad because I get back home and I've got my women there." Further fueling this perception, the documentary informs the viewer that Everard's RDs, Virginia and Rebecca, besides one woman he knew for several years, "is the nearest (he's) ever got to having a real girlfriend." Everard's disclosure of his relational past and present brings to light his heteronormative shortcomings, i.e., the fact that real women seem to be repelled by Everard despite his interest in them.

Interestingly, like Davecat, Everard creates a narrative of successful heterosexuality despite his reported bleak chances of dating a woman. But whereas Davecat tells the documentary's viewers a story of heterosexual romance, Everard's efforts toward becoming heterosexual are marked by instances of hypermasculine control and assertions of his desire for "female company." Everard's discursive strategy in his simulation of heteronormativity is the constant establishment of sexual difference through the control of (simulated) women. He photographs his dolls in "realistic" poses, applies their makeup, and brings them in public as spectators to his activities, as a means of producing that which he wished he had, and thanks to his RDs, can have. With his RDs Everard creates the world as it "should be" instead of how it is. Owning two RDs rather than following the charmed ways of monogamy, Everard produces a sense of virility. Threading together a narrative of natural masculine urges rather than sexual deviance Everard states, "I have an insatiable thirst for beautiful women of different types. One doll is not enough. If I have one I see others and I want them as well."

BBC's depiction of the idollators as men who cannot talk to women as opposed to men who have difficulty relating with people demonstrates the heteronormative ideology through which the documentary is produced. With no mention of the need for male company and the compulsive signifying of sexual difference between the men and their dolls, we see in the documentary how "heterosexualized genders form themselves through the renunciation of the possibility of homosexuality" (Butler 1995, p. 33). In fact, Everard's only mention of other men comes in a statement of resentful incredulity that women seem to prefer some "bloke at the pub with a pint of beer and a pack of fags (British slang, cigarettes)" over him. This positioning of other men as those with whom Everard can only compete (not befriend or love) "produces a domain of those whom it would be impossible to love" (Butler 1995, p. 33). Everard's origin story justifying his need for RDs, then, allows him to control his relationship to the two-sexed system. 


\section{Gordon}

A need for control within the two-sex system, however, is not unique to Everard. Midway through the documentary, Debra, a representative from the company that produces RDs informs the viewer that customers are able to choose to the most detailed degree what their dolls will look like. They pick out her clothes (and types of tongues, face, hair), do her makeup, decide when she's tired, sexually excited, and they determine what she is thinking-they are her voice. For Gordon, the third man of the documentary, this form of control is preferable to dating a real woman.

Gordon is presented as a gun-slinging, engine-revving, rejected male who has found, or settled into, the comforts and safety of his home-Gordon seems to be content now with being left alone, so long as he is with his RDs. The narrator begins Gordon's segment by informing the viewer that Gordon's father left in his infancy and that his mom raised him. As such, the documentary leaves room for the interpretation that Gordon's self-proclaimed outsider status has to do with his father's absence. And, hereafter, we are given Gordon's views on human relations; he states,

I found that it, relationships with humans are only temporary... a lot of people think that I'm cold and insensitive saying it, but everybody that is listening to this, think about when you were a five or six year old kid, think about the friends you got, how many of 'em are still friends today?

Acknowledging the presence of the camera, and thus the potential for a judging audience, Gordon's origin story takes on a confessional but persuasive tone. Gordon's justification of the idollator life stresses his natural inclination to connect to inanimate objects but also implies that humans (particularly women) are flawed in their relational capabilities. Gordon continues, "I guess I'm different than most people. I can bond with inanimate objects. I've had that poster for over twentysomething years, that car in the garage, I've had for my whole life. I just get attached to physical stuff."

Gordon describes one relationship with a woman, Patricia, who left him just prior to Christmas hence saving him money on Christmas gifts; he also discloses a story where he asked a woman he met at a party for her number only to have her call several weeks later to see if he would babysit while she went on a date. Reading these moments through the lens of a son who was abandoned by his father, the documentary locates the origin of Gordon's preference for inanimate objects with the feelings of loss, neglect, and distrust he learned to associate with human connection.

Although the only person Gordon speaks fondly of during his segment in the documentary is his mother, he, like Davecat, displays a preference for RDs to the hassle of women. Similar to Everard, Gordon explains that while he has tried to date women, he could never trust or get a woman that looks like his two RDs, Ginger and Kelly. Unlike Everard, Gordon interprets this rejection as a blessing that has allowed him to find happiness in the world of inanimate objects to which he has always felt more connected. 
Gordon's stoicism when reflecting on his ex-girlfriend gives visual merit to his contention that he has an innate bond with inanimate objects which he lacks with humans. However, in the documentary's depiction of Gordon's treatment of his RDs, the viewer gets a sense of the bitterness he feels for women. Throughout Gordon's segment, the viewer is shown footage from video recordings where he has positioned his RDs in a variety of sexual poses. The camera fixes on hooks that Gordon has installed throughout the house from which he can hang his RDs (assumedly for sexual purposes). Although Gordon expresses disgust at the thought of a woman who looks like she's "been had" by several other men (he compares such a scenario to being served an already chewed piece of meat at a restaurant), the camera pan to the ceiling hooks cue the image of meat hooks at a butcher shop. Gordon's discourse about women and his understanding of his RDs is reminiscent of the classic virgin/whore dichotomy. Women are not Gordon's equals. In fact, in order to gain Gordon's approval they cannot even be real women. Fittingly demonstrating Gordon's masculinist and misogynist views of women, he summarizes his prized possessions in one quick statement, "Three guns, two Girls."

Gordon's rejection of heteronormativity (via the rejection of real women) is what allows him to express his sense of being a real man, of "being (his) own god." In his own home Gordon can suspend the reality of the outside world where his selfdiscussed acne, bad teeth, and skinniness are unappealing to women. Interestingly, while Gordon's polygamous relationship with two (synthetic) women bolsters his position of power in his production of the two-sexed system, he interprets the same behavior in women as a threat to his becoming heterosexual. It is a problem with the category of women that occludes Gordon from a clear path to the charmed circle.

\section{Mike}

The final idollator introduced in the documentary is forty-eight year old Texan, Mike, who is at a shop where he is purchasing women's clothing and wigs. Mike informs the viewer of how he is involved in great clubs, has great friends, and some good hobbies. As he talks out his choice in clothes, it becomes apparent that Mike is picking out women's clothing he finds attractive. Mike notes that it would be crazy for him to not be looking for a woman, "somebody to share this world with." But, he also notes, "in the meantime, I'm having the most fun that I can." Mike, of all four men, is perhaps presented in the most matter of fact, colloquial of representations.

With his comment that wigs are the essential element to spend money on, we then learn that Mike has done this type of shopping before. Mike asserts: "More realistic looking, which means, more realism, better sex, every time." Mike narrates his life in ways less like the men presented before him. Mike most clearly of all the men proclaims the use of the RDs for masturbatory purposes. With excitement in his voice and his reference to sex as a "hobby," it is no surprise that when the camera pans to a close up shot of one of Mike's RDs, it is complete with hyper-sized billowing breasts in a pink, fishnet top. Mike exclaims, "Yeah, she's a cute one isn't she?" 
Further enunciating Mike's hyper-masculine performance of the (hetero)sexual male, it becomes clear that Mike holds the strongest aspirations of relating to a live woman one day while "in the meantime" using his eight RDs-with names like Misty, Jazzy, Britty, and Lexie-as a sex hobby. Mike details his gratification in waking up at three in the morning with a "raging hard on" where he can toss the RD on the bed and "go for it!" Mike offers, "I actually would like a girl in my life that knew about me in every way and was okay with it."

Thereafter, the narrator informs that unlike many RD owners, Mike has "a girlfriend" named Jody. In getting to know Jody, the viewer learns that like Mike, she is looking for an "open-minded" individual. Jody learned that Mike owns RDs and that he uses these dolls for sex. With Mike's comment that he is willing to give the RDs up for the right woman, Jody proclaims, "I can see it being long-term with Michael." Already in Jody's use of "Michael" over "Mike," the viewer hears a softening of Mike's potentially hard-core image.

Mike's RDs are a central component of his identity performance. In fact, the RDs' storage place in Mike's garage and the work he puts into their appearance is reminiscent of toys that the stereotypical or conventional grown man often cherishes-cars, power tools, and plasma televisions. The centrality of the RDs climaxes when they are in attendance at his birthday party with Jody.

Mike's simultaneous desire to have his RDs in his life and to date Jody demonstrates the discursive pressures of masculinity. As mentioned with Gordon, men are often praised for their "success" with multiple women. However, a sign of becoming a man is fighting these "natural urges," settling down with a woman, and starting a family. Inside of his dilemma, Mike must choose between the masculinity of bachelor life and that of the "charmed circle" (Rubin 1984). As we see at the end of the documentary, Mike cannot (nor does he try to) control Jody. But he illustrates that he cannot be controlled by her either. Thus while Mike offers a less objectifying understanding of women in his overall engagement with Jody and his RDs, his segment of the documentary seems to imply that sexual urges in men are not meant to be tamed.

\section{Conclusion: Confessions of an Idollator}

As detailed throughout this essay, RDs serve as the primary or sole source of "female" company for the men in BBC's documentary. In the case of some of the men, what began as an alternative choice due to the inability to attract real women, has become their preferred way of living. For all of the men, existing in the everyday with a doll takes away the vulnerability and fear of rejection they associate with dating actual women. Despite acting as a safety net, each man discursively acknowledges that the dolls complicate his access to a norm abiding life, and so was the focus of this essay.

Becoming narratives are reflective discourses in which these men confess their rationale for dating silicone women rather than real women. Importantly, the function of these narratives is not simply descriptive or confessional; rather these discourses interact with, are confined by, and thus, be-come identifiable in relation 
to normalizing structures. As such, these narratives do open the choices of the men to stigmatization. Notably, however, although their becoming is centered on the assertion of a sexuality, the idollators in BBC's documentary say little about their sexual orientation. Instead, the female-likeness of their doll(s) speaks for itself; is it that the men want someone who looks like their doll(s) and therefore are heterosexual? Not quite.

We have argued that RDs serve as vessels through which these men, in Halperin's (1990) words, "co-opt the feminine" (p. 145). RD's mimicry of the conventionally idealized female body allows the idollators to simulate the practices of a heterosexual romance. Interestingly, their preference (or willingness to settle) for innate objects over real people never prompts a discussion about the sexuality of any of these men within the narrative of the documentary. Demonstrating the weight of heterosexuality, the men's violations of the charmed circle are framed in the documentary as the consequence of unrequited heterosexual desires. Ownership of more than one RD along with the exaggerated femininity of the RDs (giant breasts, slender build, long hair) serve as signs that these men plainly desire real womenand not that they actually desire the control made possible only by dating a piece of silicone. What makes these men queer in their ways of living, then, is not simply that they own a sex doll but rather the temporalities and spatiality's in which they exist. The amount of time the documentary's men are seen at home in the private sphere with their RDs and not out with friends and family locates them far off the beaten path of the "scripted" life_- "namely, birth, marriage, reproduction, death" (Halberstam 2005, p. 2). In short, "our privileged notions of time, (space), and activity" pathologize the modes of becoming as seen in Guys and Dolls, including those that transcend the sexual (Halberstam 2005, p. 5).

As we assessed the documentary, we both discovered that in learning to suspend our own judgments about the men, particularly upon multiple viewings, we more closely attended to the men as men who are implicated in what some might call a taboo and/or stigmatized realm of disclosure. The documentary invites, what we term, a voyeuristic hetero-spectacle as it brings the viewer into the homes of each man it features, thus contaminating their sterile safer space with the logic and judgment of the charmed circle. As each man describes intimate details of his relationship with his $\mathrm{RD}(\mathrm{s})$ the camera functions as a confessional, present because these men have sinned (by way of judgments within the charmed circle). But the camera does not grant the men penance; instead it represents knowledge about this sexual co-culture to be consumed and conquered by the common sense of heteronormativity. The idollators' descriptions of the mechanics of their privately fabricated heterosexuality become an admission of sexual deviance when read through the documentary's heteronormative lens. Echoing Butler (1993), and far from serving a subversive function by highlighting the constant performative maintenance requisite to heterosexuality's naturalization, the documentary "reidealize[s] heterosexual norms without calling them into question" (p. 231).

Guys and Dolls becomes a potentially subversive text when read through the logic of queer theory. Instead of consuming instances of heteronormative ineptitude as gratifying moments that shore up the logic of real heterosexuality, a queer reading of the text provides the tools to trouble the binary logic of the two-sexed 
system. Interpreting the documentary in this way, we see the counterpart to Halberstam's (1998) findings in Female Masculinity-the production of femininity by male bodies. And while the men of Guys and Dolls displace their performance of femininity onto a proper feminine vessel, this controlled masculine performance of the feminine disrupts the naturalized categories of sex and gender and their respective articulations. Further, it challenges the status of heterosexuality as a natural monolithic desiring system since the male object of desire-woman-is exposed as a performative construct rather than an essential characteristic of certain bodies.

Also highlighted is the role that framing of a media text plays in the maintenance of hegemonic systems. That is, the documentary's heteronormative framing of the men is not a neutral way to make sense of these men and their synthetic dolls. As outlined throughout this essay, there are gaping holes in any logic that would deem these men heterosexual. However, rather than discussing the pressures and disadvantages of attempting to live up to the limited gender positions available within heteronormative systems or even questioning the monolithic myth of heterosexuality, the documentary frames these men as deviant or worthy of pity due to their failure to live up to the ideal.

We would like to conclude with a discussion for further study and a note on the implications of becoming in negotiating and understanding sexual identities. We believe this essay contributes to a larger humanistic understanding of assessing how we, as individuals, are coping in our becoming. As the globe continues to grow in population, and as new technologies are ubiquitous to our ways of relating, we must continue to work to understand how our lives are being re-presented in media texts, particularly within documentaries which (at some level) purport to give us an objective glance into the everyday lives of their subjects. While previous studies dealing with gender and sexuality in media texts have observed the ways heteronormative readings are overdetermined within popular programs (Battles and Hilton-Morrow 2002; Erni 1998; Kim et al. 2007; Lacroix and Westerfelhaus 2005; Lindgren and Lelievre 2009), in our dealing with a similar text we found that embracing the logic of becoming can create constructive uses for ideologically problematic texts. Perhaps future research could examine other popular media texts featuring RDs including the 2007 film Lars and the Real Girl, the appearance of Davecat on an episode of The Learning Channel's Strange Addictions, and a 2012 episode of House in which an idollator is hospitalized and his RD is initially suspected as the source of his illness. Pushing this further, future research could explore online forums in which idollators post about their RDs and their responses to media representations of the idollator and RD relationship.

Sophistic thinker Isocrates (2001) suggested that the self-reflective use of rhetoric was vital for both self improvement and for the good of society. It seems to us that Isocrates' philosophy applies here as the narratives we tell ourselves construct and direct who and how we become within the larger systems of society. The stories the men tell about themselves in the documentary paints a complex and complicating picture of women and humanity more generally. Understanding our own identities as narratives of becoming that can persist, pivot, and change direction allows us to challenge ourselves in who we are, how we see others, and whether we want to 
"keep [this] particular narrative going" (Giddens 1991, p. 54). ${ }^{8}$ In short, while the theory of becoming serves a descriptive function in understanding the contours of postmodern identity, we hope this essay demonstrates its importance as a selfreflective and practical tool toward understanding better the complex negotiations of identity in everyday life.

Acknowledgments The authors would like to thank Linda Baughman, Rosie Russo, and members of the Colorado State University, Communication Studies Department Writing Group for their time and invaluable comments with various stages of drafts.

Open Access This article is distributed under the terms of the Creative Commons Attribution License which permits any use, distribution, and reproduction in any medium, provided the original author(s) and the source are credited.

\section{References}

Abele, S., \& Holt, N. (2007). Guys and dolls [Documentary]. Available from the British Broadcasting Corporation, Broadcasting House, United Kingdom: Portland Place London W1A 1AA.

Battles, K., \& Hilton-Morrow, W. (2002). Gay characters in conventional spaces: Will and Grace and the situation comedy genre. Critical Studies in Media Communication, 19(1), 87-105.

Benson, T., \& Anderson, C. (1989). Reality fictions: The films of Frederick Wiseman. Carbondale: Southern Illinois University Press.

Berlant, L., \& Warner, M. (1998). Sex in public. Critical Inquiry, 24(2), 547-566.

Butler, J. (1990). Gender trouble: Feminism and the subversion of identity. New York: Routledge.

Butler, J. (1993). Bodies that matter: On the discursive limits of 'sex'. New York: Routledge.

Butler, J. (1995). Melancholy gender/refused identification. In M. Berger, B. Wallis, \& S. Watson (Eds.), Constructing masculinity (pp. 21-36). New York: Routledge.

Carrion, V. G., \& Lock, J. (1997). The coming out process: Developmental stages for sexual minority youth. Clinical Child Psychology and Psychiatry, 2(3), 369-377.

Connell, R. W. (2003). The big picture: Masculinities in recent world history. In J. Weeks, J. Holland, \& M. Waites (Eds.), Sexualities \& society: A reader (pp. 46-56). Oxford: Polity Press.

Deleuze, G., and Guattari, F. (1987). A thousand plateaus: Capitalism and schizophrenia. (B. Massumi, Trans.). Minneapolis: University of Minnesota Press.

Diamond, M., \& Sigmundson, K. (1997). Sex reassignment surgery at birth: Long-term review and clinical implications. Archives of Pediatric and Adolescent Medicine, 151(3), 298-304.

Dow, B. J. (2001). Ellen, television, and the politics of gay and lesbian visibility. Critical Studies in Media Communication, 18(2), 123-140.

Dunne, G. A. (2003). A passion for 'sameness'? Sexuality and gender accountability. In J. Weeks, J. Holland, \& M. Waites (Eds.), Sexualities \& society: A reader (pp. 57-68). Oxford: Polity Press.

Erni, J. N. (1998). Queer figurations in the media: Critical reflections on the Michael Jackson sex scandal. Critical Studies in Mass Communication, 15(2), 158-180.

Foucault, M. (1978). The History of Sexuality Volume 1: An Introduction. (R. Hurley, Trans.). New York: Random House.

Giddens, A. (1991). Modernity and self-identity: Self and society in the late modern age. California: Stanford University Press.

Gross, L. (2005). The past and the future of gay, lesbian, bisexual, and transgender studies. Journal of Communication, 55(3), 508-528.

Halberstam, J. (1998). Female masculinity. North Carolina: Duke University Press.

Halberstam, J. (2005). In a queer time and place: Transgender bodies, subcultural lives. New York: New York University Press.

\footnotetext{
${ }^{8}$ Giddens (1991) argues that our perception of identity as coherent and consistent comes from an active effort and desire to make sense of our lives within an ongoing "project of the self" (p. 5).
} 
Hale, C. J. (2003). Leatherdyke boys and their daddies: How to have sex without women or men. In R. J. Corber \& S. Valocchi (Eds.), Queer studies: An interdisciplinary reader (pp. 61-70). Malden: Blackwell.

Halperin, D. M. (1990). One hundred years of homosexuality: The new ancient world and other essays on Greek love. New York: Routledge.

Isocrates (2001). From antidosis. In P. Bizzell \& B. Herzberg (Eds.), The rhetorical tradition: Readings from classical times to the present (2nd ed., pp. 75-79). Boston \& New York: Bedford/St. Martin's.

Jackson, S. (2003). Heterosexuality, heteronormativity, and gender hierarchy: Some reflections on recent debates. In J. Weeks, J. Holland, \& M. Waites (Eds.), Sexualities \& society: A reader (pp. 69-84). Oxford: Polity Press.

Jardine, A. (1985). Gynesis: Configurations of women and modernity. Ithaca: Cornell University Press. Jolly, M. (2001). Coming out of the coming out story: Writing queer lives. Sexualities, 4(4), 474-496.

Kim, J. L., Sorsoli, C. L., Collins, K., Zylbergold, B. A., Schooler, D., \& Tolman, D. L. (2007). From sex to sexuality: Exposing the heterosexual script of primetime network television. Journal of Sex Research, 44(2), 145-157.

Lacroix, C., \& Westerfelhaus, R. (2005). From the closet to the loft: Liminal license and socio-sexual separation in Queer eye for the straight guy. Qualitative research Reports in Communication, 6(1), 11-19.

Lindgren, S., \& Lelievre, M. (2009). In the laboratory of masculinity: Renegotiating gender subjectivities in MTV's Jackass. Critical Studies in Media Communication, 26(5), 393-410.

Lofland, J., Snow, D., Anderson, L., \& Lofland, L. H. (2006). Analyzing Social Settings: A Guide to Qualitative Observation and Analysis (4th ed.). Belmont: Wadsworth.

McLean, K. (2007). Hiding in the closet? Bisexuals, coming out and the disclosure imperative. Journal of Sociology, 43(2), 151-166.

Meyer, M. D. E. (2007). On remembering the queer self: The impact of memory, trauma and sexuality on interpersonal relationships. Sexuality and Culture, 11(4), 18-30.

Money, J. (1975). Albatio penis: Normal male infant sex-reassigned as girl. Archives of Sexual Behavior, $4(1), 65-71$.

Ott, B. L., \& Aoki, E. (2004). Counter-imagination as interpretive practice: Futuristic fantasy and The Fifth Element. Women's Studies in Communication, 27(2), 149-176.

Patton, C. (1993). Tremble, hetero swine. In M. Warner (Ed.), Fear of a queer planet: Queer politics and social theory (pp. 143-177). Minneapolis: University of Minnesota Press.

Rubin, G. (1984). Thinking sex: Notes for a radical theory of the politics of sexuality. In C. Vance (Ed.), Pleasure and Danger (pp. 267-312). New York: Paragon Press.

Sedgwick, E. K. (1990). Epistemology of the closet. Berkeley: University of California Press.

Simon, W. (2003). The postmodernization of sex. In J. Weeks, J. Holland, \& M. Waites (Eds.), Sexualities \& society: A reader (pp. 22-32). Oxford: Polity Press.

Sloop, J. (2004). Disciplining gender: Rhetorics of sex identity in contemporary U.S. culture. Amherst and Boston: University of Massachusetts Press.

Stein, A. (2003). Becoming lesbian: Identity work and the performance of sexuality. In J. Weeks, J. Holland, \& M. Waites (Eds.), Sexualities \& society: A reader (pp. 132-142). Oxford: Polity Press.

Turner, V. W. (1974). Dramas, Fields, and metaphors: Symbolic action in human society. Ithaca: Cornell University Press.

Weeks, J. (1986). Sexuality. London: Routledge. 